\title{
Solar Rooftop Power Generation System by Using IOT (Arduino \& Blynk)
}

\author{
Raj Chavan ${ }^{\# 1}$, Avinash Kolekar ${ }^{\# 2}$ \\ \# Department of Mechanical Engineering, VPKBIET, Baramati \\ Maharashtra, India. \\ * VPKBIET, Baramati, \\ Maharashtra, India.
}

\begin{abstract}
The Energy requirement increases day by day as per more electronic and electrical equipment are used in today's life at home. But there is the imbalance in between due to demand of electricity generation. As there is the shortage of nonrenewable energy resources, so this is the time to get switch towards the renewable energy resources like solar, wind, tidal, biogas etc. This project is based on a Solar Rooftop Generation system using the Blynk and AC mains with Relay modul \& Arduino controller. This proposed of uses of the Solar cell, inverter, smart energy meters and Arduino controller \& Blynk. The main advantage of system is the to increase the energy efficiency in its used and supply for domestic purpose and also to saves the money and to show the result in accurate manner and data regarding its used and its energy generation.
\end{abstract}

Keywords:- Solar Cell, Arduino, Net meter, Blynk, Invertor.

\section{INTRODUCTION}

As per the requirement and the use of energy the fossil fuels are nearly at an end. So, to find the new form of energy as per requirement and availability with the clean and ecofriendly energy by decreasing the global warming together with economic developments. As the oil and gas reserves are nearly at its end in 45 to 50 years respectively and coal reserves could able be at its 210 years accordingly the use and its future use. Due to this reason it is necessary to search for the alternate energy sources which can be capable of preventing the requirement of energy as per demand in today and in future use and by not giving its contribution for increasing the global warming. Renewable energy resources like Solar, Wind, Tidal, etc. Which are known as the Renewable energy sources that are the best alternative energy sources can be used, especially as result of concern on energy sources like Wind, Sun, biogas, geothermal and hydrogen, etc. But by use of this energy does not actual stand in front of efficiency and effectiveness, for the relative purpose the system used different energy's by combining there used to overcome its disadvantage by increase its efficiency and accuracy with effectiveness.
To use the renewable energy resources for daily purpose need, we have a issued as it is not reliable. Means to generate the consistence amount of energy as per requirement in household need like $\mathrm{AC}$, Fans, Refrigerator, etc. A form of energy is not sufficient. To overcome the related problem this system, combine the Solar cell with AC mains from MECB which helps to maintain the power supply for the daily requirement of home. As well as Blynk app represents the current situation of resources of its work with accurate

\section{LITERATURE REVIEW}

The solar energy is used to satisfy the required availability of load for the home. Arduino and Blynk is used with relay given to the AC main and MSEB where the Blynk shows the data of energy generate and used in its library. In first system to find the data the PLC based system is used to monitor the data of energy generation. Where we are going to replace the PLC with Arduino. In PLC and SCADA system define the statical information regarding energy. As PLC modems are installed in each solar module but we will used WIFI module to monitor its status.

For the efficient operation of solar system, a tracking systems is used which track the sun's radiation. An automatic position control of solar panel used to rack the sun in morning till evening which is connected to AC mains through relay for providing the work. The stepper motor is used for position the solar panel which is controlled by Arduino.as by positioning the solar panel which is used to charge the battery, with continuously generation of energy.

For the smart homes the energy used is very much important by minimizing the cost of used and to fulfilled the energy requirement for the purpose the Blynk and Arduino is used to monitor the data which present the needful results. As the wind energy and tidal energy as its wok on water to generates the electricity which is monitor the battery level and bank to stable energy module maintain. 
Solar panel used to capture the radiation, but tracker is used gyration of earth and rotates by its axis following the sun to gets needful efficiency. The purpose of tracking is to increase the efficiency output of panel for further used.

In existing system PLC module is used to monitor the used of appliance which system gets bulky and complex. Due to which installation gets bulky and cost of system increase. The use of Arduino avoids the problem as its size and shape is small and can handle the system user in a friendly manner.

\section{PROPOSED METHODOLOGY}

By installing the solar system with Arduino and Blynk used to avoid losses and increase the efficiency of system to generate the energy.

$>$ The supply is given to load by using the relay module which is connected before the load.

$>$ If Solar system output is insufficient to tackle the load, the circuit is switched to AC mains to the MSCB supply.

$>$ The process gets visualized in a Blynk app in mobile, which shows the generation and use of consumption by home appliance.

$>$ WIFI module is available that provides the output regarding switching the mode of use.

\section{DESIGN PROCESS}

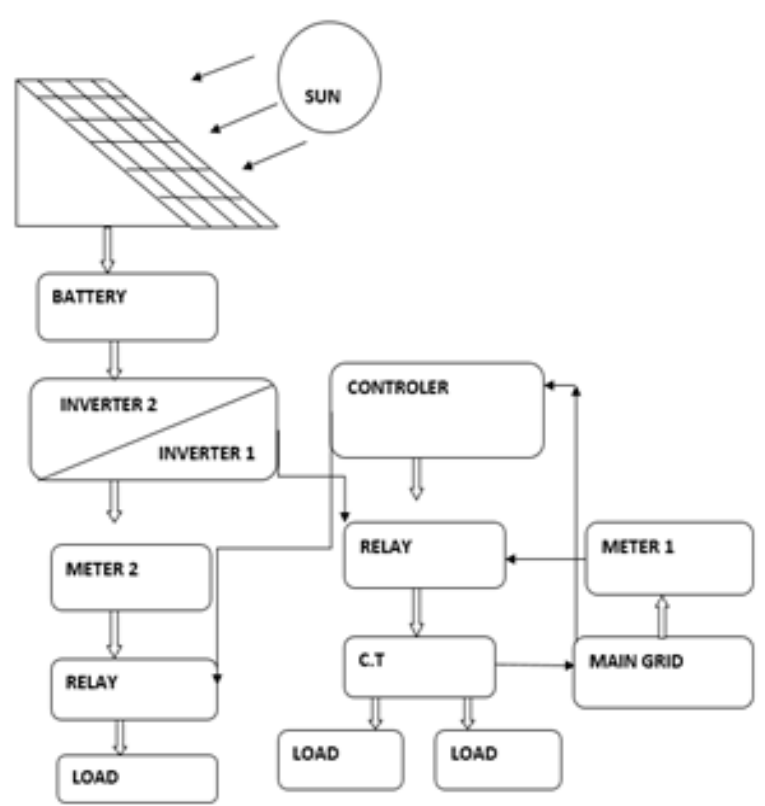

Fig 1:- Block-diagram of Solar Rooftop Power Generation System by Using IOT (Arduino \& Blynk)

The energy which gets generates in solar module where solar energy is converted into electrical energy. As shown in figure the energy which gets converted it is DC energy. But we know that at home appliance requirement is of $\mathrm{AC}$ supply, so the invertor is used of $12 \mathrm{v}$ that convert the DC into AC. Where in the given system as shown if a load is insufficient for the household work the relay provides the signal to Arduino where it disconnects the solar used by connecting with the MECB load through AC main. The situation occurs as during night time where energy generation is limited where light source is totally disconnected. As the solar system is in sufficient to run the load. So, we moved to words AC mains, as solar keeps its generation of energy which gets store to the battery. As controller is basically used to switch the power from solar to AC.

Where output of solar energy is totally depending on solar (SUN). As we know that light availability is totally different in different season like Summer, Winter, Rainy season. Second condition arises where the output of solar is greater than required load mostly in summer season. That is when light intensity is higher than requirement the extra energy remains which gets store in battery or given to AC mains. Where two net metering is used to calculate the power by MECB and the power by solar. All the process is visible in Blynk. The relay module is provided before the loads gets connect with Arduino as relay is used so it can handle the sudden impact that strike before on it. WIFI module is used as a smart device that where makes the system easy to work where it is used to transfer the output to the Arduino and Blynk.

\section{$>$ Blynk}

Blynk which was design for the IOT (Internet of Things). It is one of the popular IOT Platform.it is used to control the hardware remotely, also display the sensor data, it can store the data, visualized it and do many other different things. Also, by using the Blynk library you can connect over 400 hardware models (including ESP8266, Node MCU, ESP32, all types of Arduino, Raspberry Pi, etc.) to the Blynk Cloud.

There are three major components in the platform:

Blynk App - allows to you create amazing interfaces for your projects using various widgets we provide.

Blynk Server - responsible for all the communications between the smartphone and hardware. We can use our BlynkCloud or run your private Blynk server locally. It's open-source, could easily handle thousands of devices and can even be launched on a Raspberry Pi.

Blynk Libraries - for all the popular hardware platforms - enable communication with the server and process all the incoming and out coming commands.

Now imagine: every time you press a Button in the Blynk app, the message travels to the BlynkCloud, where it finds its way to reach to your hardware. It works the same in the opposite direction and everything happens in a Blynk of an eye. 


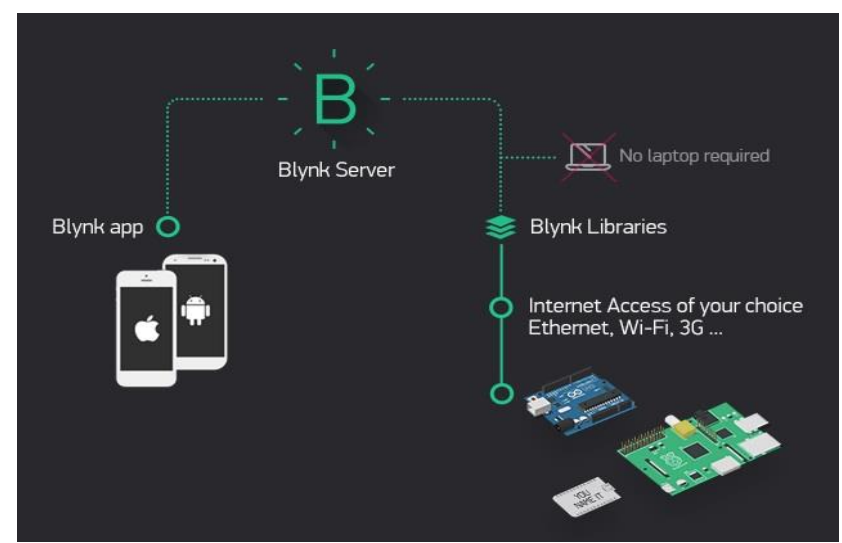

Fig 2:- Block Diagram

\section{SIMULATION RESULTS}

By using the $100 \mathrm{~W}$ solar panel system with battery and inverter depends on $12 \mathrm{~V}$ and power. $100 \mathrm{~W}$ prototype model can be used that can generate the $12 \mathrm{~V}$ supply in full sunny days.

If the load is less than $100 \mathrm{~W}$ then solar output is connected to the load through controller.

$>$ If load is greater than the $100 \mathrm{~W}$ then controller switches load to the AC mains. At that time output of solar panel is stored in the battery.

- To find a requirement of solar panels and inverter and also the optimizer.

1. Highest unit -128 unit of Oct.

Note - Per $1 \mathrm{KW}$ of solar panel $=1400$ Unit Yearly

$=128 \times 12 / 1400$

$=1.09 \mathrm{KW}$

$=1 \mathrm{X} 1000 \mathrm{~W}$.

Note - If the value in KW is greater than the sanction load given by the MSEDC Mahavitaran then 1st we have to increase the sanction load, so to apply the solar rooftop system.

\section{- Panel Requirement.}

As for $1 \mathrm{KW}=1 \mathrm{X} 1000 / 325$

$=3.07$

$=3$ Panel required

As the Panels is selected check whether the area is sufficient or not for applying the system.

As, for

$1[\mathrm{KW}]-10 \mathrm{sq}$. Area required

$10[\mathrm{KW}]-100 \mathrm{sq}$.

$50[\mathrm{KW}]-500 \mathrm{sq}$.

$100[\mathrm{KW}]-1000 \mathrm{sq}$.

Note - we required 100 sq. Area.
ISSN No:-2456-2165

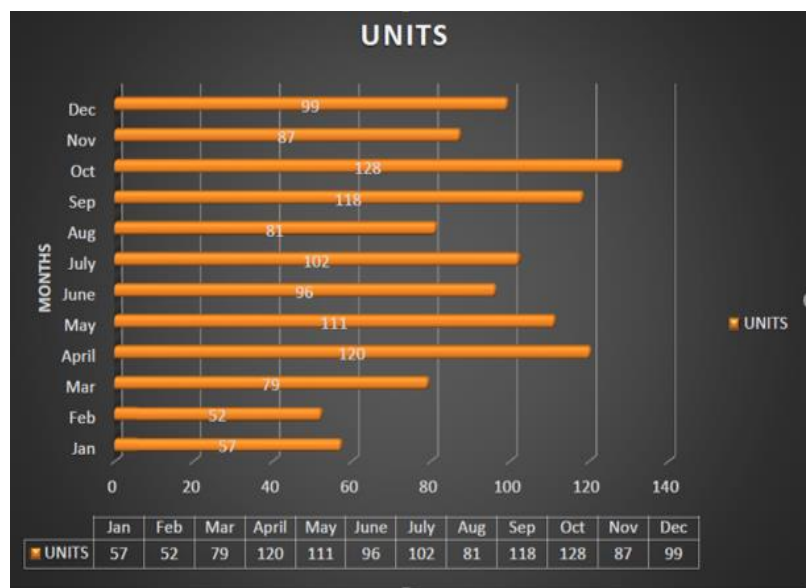

Fig 3:- Chart of Solar Energy generated in every month

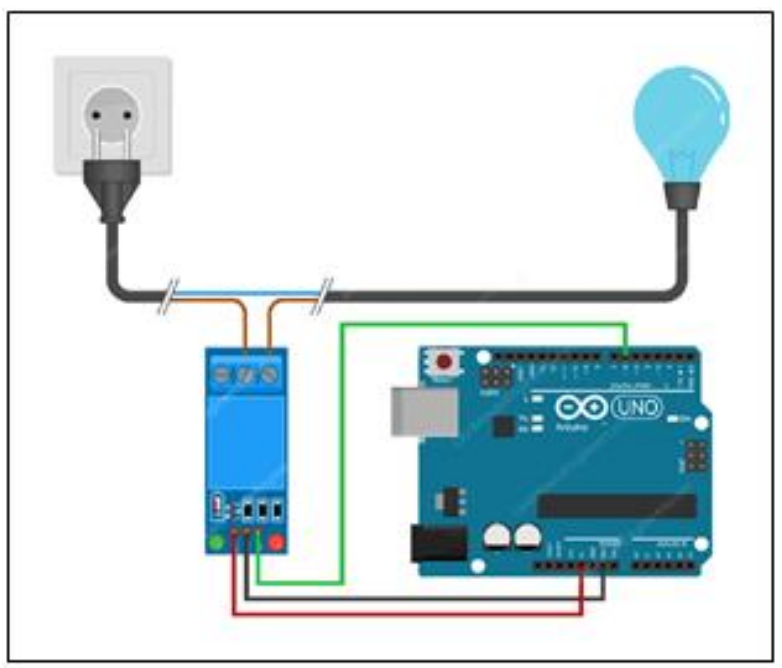

Fig 4:- Arduino Relay Control

LED Blinking is the first and common beginner program, in which a LED blink is carried out by some delay. So instead of using the LED bulb we are going to use an AC bulb and will get blink with some delay used.

Whenever we are going to use an AC Appliance in our circuits, we will used relay. So, in this we are combining the Arduino with Relay by using of NPN transistor to control relay without using a relay driver IC.

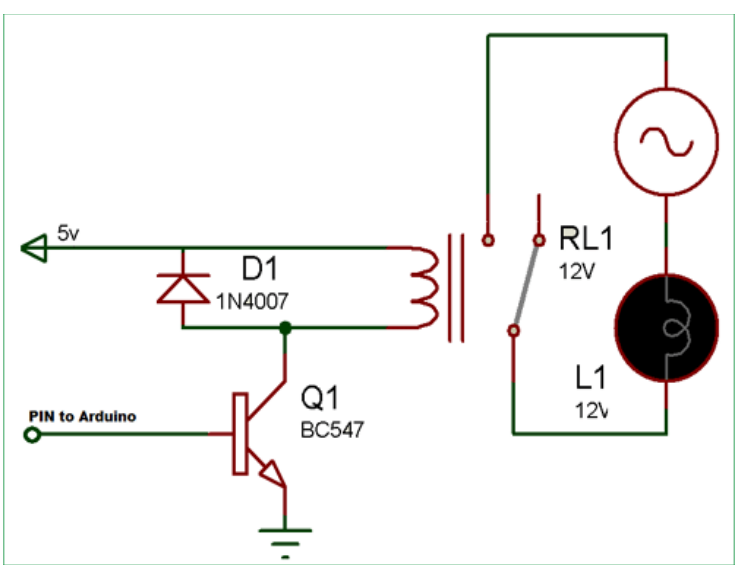

Fig 5:- Circuit Diagram 


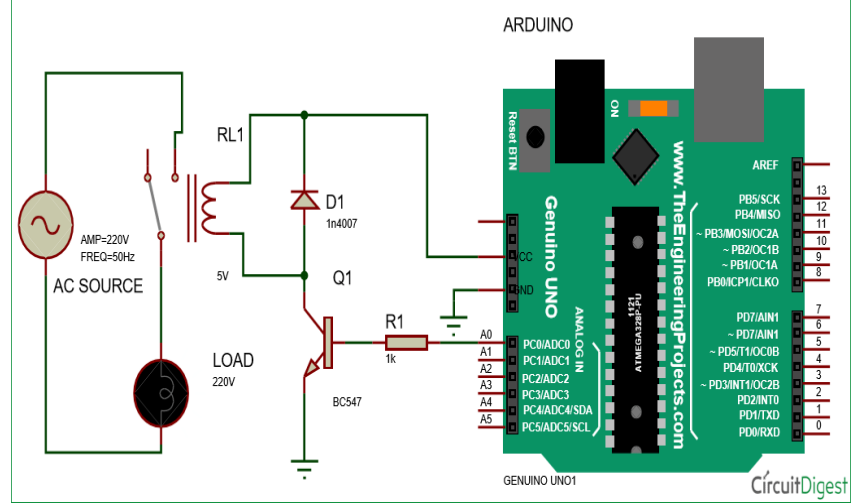

Fig 6:- Circuit Diagram

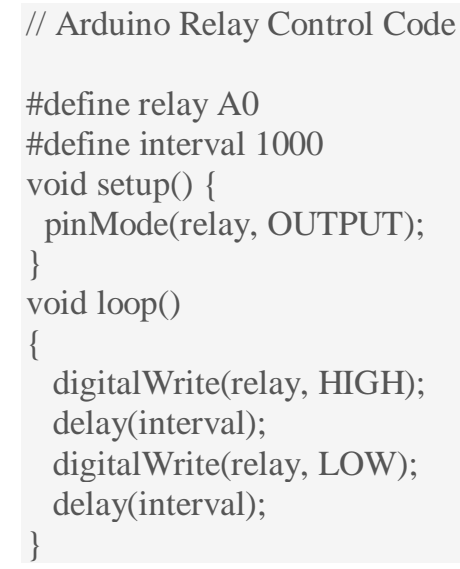

The circuit diagram using Controller as a Relay name ESP8266 is shown below. As a single channel relay module is used in the circuit diagram.

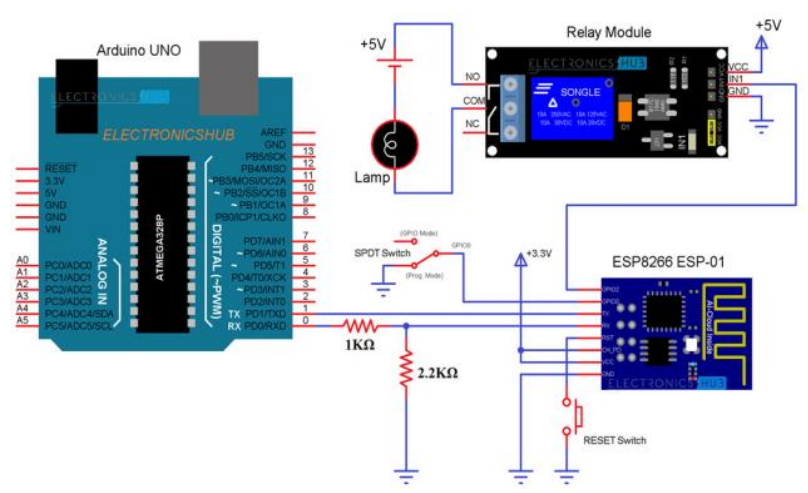

Fig 7:- Circuit Diagram

\section{CONCLUSION}

The paper presents a design of a photovoltaic solar power system which can be used for residential homes that have installed renewable energy sources to save an energy cost, which is important for both energy consumption and generation. Solar power generation system is considered as a green and clean energy, the purposed of using the solar energy system as to increase the Efficiency of using the energy that gets generate without losses and accuracy of data achieved and maintenance free with help of Blynk and Arduino.

\section{REFERENCES}

[1]. Young-Sung Son and Kyeong-Deok Moon, "Home energy management system based on power line communication," in Proc. IEEE International Conference on Consumer Electronics, Las Vegas, USA, pp. 115-116, Jan. 2010.

[2]. Young-Sung Son and Kyeong-Deok Moon, "Home energy management system based on power line communication," IEEE Trans. Consumer Electron., vol. 56, no. 3, pp. 1380-1386, Aug. 2010.

[3]. Jinsoo Han, Chang-Sic Choi, Wan-Ki Park, and Ilwoo Lee, "Green home energy management system through comparison of energy usage between the same kinds of home appliances," in Proc. IEEE International Symposium on Consumer Electronics, Singapore, pp. 1-4, Jun. 2011.

[4]. Chia-Hung Lien, Hsien-Chung Chen, Ying-Wen Bai, and Ming-Bo Lin, "Power monitoring and control for electric home appliances based on power line communication," in Proc. IEEE International Instrumentation and Measurement Technology Conference, British Columbia, Canada, pp. 21792184, May 2008.

[5]. Saeed Jahdi and Loi Lei Lai, "Grid integration of wind-solar hybrid renewable using AC/DC converters as DG power sources," in Proc.World Congress Sustainable Technologies, London, UK, pp. 171-177, Nov. 2011.

[6]. Hayato Yamauchi, Kosuke Uchida, and Tomonobu Senjyu, "Advanced Smart Home," in Proc. IEEE International Conference on Harmonics and Quality of Power, Hong Kong, China, pp. 130-135, Jun. 2012.

[7]. Jinsoo Han, Chang-Sic Choi, Wan-Ki Park, Ilwoo Lee, and Sang-Ha Kim, "Smart home energy management system including renewable energy based on ZigBee and PLC," in Proc. IEEE International Conference on Consumer Electronics, Las Vegas, USA, pp. 544-545, Jan. 2014. 